\title{
Linear sweep voltammetric studies on the supramolecular complex of alizarin red $S$ with lysozyme and determination of lysozyme
}

\author{
WEI SUN*, NA ZHAO, XUELIANG NIU, YAN WANG and KUI JIAO \\ Key Laboratory of Eco-Chemical Engineering of Ministry of Education, College of Chemistry and \\ Molecular Engineering, Qingdao University of Science and Technology, Qingdao 266042, PR China \\ e-mail: sunwei@qust.edu.cn
}

MS received 28 June 2007; revised 30 January 2008

\begin{abstract}
An electrochemical method for the determination of lysozyme (LYS) based on its interaction with alizarin red S (ARS) was established by linear sweep voltammetry in this paper. The electrochemical behaviour of ARS with LYS was investigated on a dropping mercury working electrode in $0.2 \mathrm{~mol} / \mathrm{L} \mathrm{pH}$ 4.8 Britton-Robinson (B-R) buffer solution. ARS showed a sensitive second order derivative linear sweep voltammetric reductive peak at $-0.42 \mathrm{~V}$ (vS SCE). After the addition of LYS, the reductive peak current of ARS decreased without the shift of the reductive peak potential and no new waves appeared, which was due to the formation of a supramolecular complex of ARS with LYS in the solution. The stoichiometry of the ARS-LYS complex was further calculated by the electrochemical data with the results of the binding ratio as $3: 1$ and the binding constant as $2.82 \times 10^{14}$. Under the selected conditions, the decrease of the second order derivative linear sweep voltammetric reductive peak current of ARS was in proportion to the LYS concentration in the range from 0.8 to $35.0 \mathrm{mg} / \mathrm{L}$ and the detection limit of LYS was calculated as $0.52 \mathrm{mg} / \mathrm{L}(3 \sigma)$. Different kinds of LYS samples were detected satisfactorily with this method.
\end{abstract}

Keywords. Alizarin red S; lysozyme; linear sweep voltammetry; interaction; determination.

\section{Introduction}

The determination of protein is of great importance in the field of bioanalytical chemistry. Studies on the interaction of small molecules with protein can also be used for the understanding of the structures and functions of protein. ${ }^{1}$ Many analytical methods had been proposed for protein investigation including UV-Vis absorption spectrophotometry, ${ }^{2,3}$ fluorometry, ${ }^{4,5}$ light scattering technique ${ }^{6,7}$ and electroanalytical methods. ${ }^{8,9}$ In recent years electrochemical methods had been greatly developed in bioanalytical chemistry with the advantages of low-cost, fast response and cheap instrumentation. Since the electrode reaction takes place on the interface of electrode/ solution, it is especially suitable for small amount of samples with higher sensitivity. ${ }^{10}$ Different electrochemical methods had been proposed for the determination of biomolecules such as proteins, DNA and glycosaminoglycan. For example, Timaya et al established an electrochemical DNA quantification method based on aggregation of DNA induced by

*For correspondence
Hoechst $33258 .^{11}$ Li et al investigated the electrochemical behaviours of the interaction of basic brown G with DNA and applied to DNA determination. ${ }^{12}$ Jiao et al synthesized a new Co(II) complex of $\mathrm{Co}(\mathrm{bbt})_{2} \mathrm{Cl}_{2}$ and studied the interaction of the Co(II) complex with fish sperm dsDNA. ${ }^{13}$ Sun et al applied some organic dyes as the electrochemical probes for the determination of protein ${ }^{14,15}$ and heparin. ${ }^{16,17} \mathrm{Lu}$ et al also studied the interaction of bovine serum albumin with acid cyanine $5 \mathrm{R}$ and applied to the protein analysis. ${ }^{18}$

Lysozyme (LYS) is an enzyme commonly present in egg white, tears and other secretions. It is responsible for breaking down the polysaccharide walls of bacteria by hydrolysing reaction and thus provides some protections against infection. LYS is a compact protein of 129 amino acids, which folds into a compact globular structure. The function of LYS is to hydrolyse the $\beta(1-4)$ glycosidic bond between residues of $N$-acetylmuramic acid (NAM) and $N$ acetylglucosamine (NAG) in certain polysaccharides. ${ }^{19,20}$ So it is important to develop a sensitive and convenient method for LYS determination. Chen et al studied the interaction of LYS with 
diethyl-flavon-7-yl phosphate by electrospray ionization tandem mass spectrometry (ESI-MS) and fluorescence method, which indicated that the binding reaction was based on electrostatic power. ${ }^{21}$ Yang et al applied fluorescence spectroscopy to study the interaction of LYS with naringein or naringin and the results indicated that both of them formed non-covalent compounds with LYS through hydrophobic interaction force. ${ }^{22}$ Wang et al also investigated the interaction of a copper (II) complex with LYS by UV-Vis spectrophotometric method. ${ }^{23}$

In this paper, the interaction of an electroactive dye of alizarin red S (ARS) with LYS was studied in the solution by the second order derivative linear sweep voltammetry. The results indicated that a supramolecular complex was formed in the selected $\mathrm{pH}$ 4.8 Britton-Robinson (B-R) buffer solution, which caused the changes of the reductive peak current of ARS without the movement of reductive peak potential. The decrease of peak current was in proportion to the LYS concentration and further used to establish a sensitive electroanalytical method for LYS determination. The proposed method was successfully applied to the LYS samples detection with satisfactory results.

\section{Experimental}

\subsection{Chemicals}

A $1.0 \times 10^{-3} \mathrm{~mol} / \mathrm{L}$ alizarin red $\mathrm{S}$ (ARS, Shanghai Zhongxin Chemical Reagent Company, China) stock solution was prepared by dissolving it directly in doubly distilled water. Lysozyme (LYS, $20000 \mathrm{U} / \mathrm{mg}$ ) was purchased from Bio. Basic Inc. (China) and the calculation for LYS was based on a molecular mass of $16000 \mathrm{~g} / \mathrm{mol}$. A $1.0 \mathrm{~g} / \mathrm{L}$ LYS stock solution was prepared and stored in $4{ }^{\circ} \mathrm{C}$ refrigerator. A series of $0.2 \mathrm{~mol} / \mathrm{L}$ Britton-Robinson (B-R) buffer solution was used as the reaction medium and the supporting electrolyte. All the chemicals used were of analytical reagents grade and doubly distilled water was used throughout.

\subsection{Apparatus}

The second order derivative linear sweep voltammetric determination was obtained on a model JP303 polarographic analyzer (Chengdu Apparatus Factory, China) with a traditional three-electrode system composed of dropping mercury working elec- trode (DME), a saturated calomel reference electrode (SCE) and a platinum wire auxiliary electrode. The $\mathrm{pH}$ values were measured with a pHS-25 acidity meter (Shanghai Leici Instrument, China). All the experiments were carried out at the temperature of $20^{\circ} \mathrm{C} \pm 2{ }^{\circ} \mathrm{C}$.

\subsection{General procedure}

Into a $10 \mathrm{ml}$ colorimetric tube the solutions were added in the following sequences: $0.5 \mathrm{~mL}$ of $1.0 \times 10^{-3} \mathrm{~mol} / \mathrm{L}$ ARS solution, $3.0 \mathrm{~mL}$ of $\mathrm{pH} 4.8 \mathrm{~B}-\mathrm{R}$ buffer solution and an appropriate amount of LYS solution. The mixed solution was shaken homogeneously and diluted to the scale with water. The final solution was reacted for $20 \mathrm{~min}$ and the second order derivative linear sweep voltammetric curves of the solution was scanned in the potential range from $-0 \cdot 1$ to $-0.8 \mathrm{~V}$ (vs SCE) with the peak current $\left(I_{\mathrm{p}}{ }^{\prime \prime}\right)$ at $-0.42 \mathrm{~V}$ recorded. At the same time, the solution of ARS without the addition of LYS was also scanned and the peak current $\left(I_{\mathrm{p} 0}{ }^{\prime \prime}\right)$ was obtained. The differences of the peak current $\left(\Delta I_{\mathrm{p}}{ }^{\prime \prime}=I_{\mathrm{p} 0}{ }^{\prime \prime}-I_{\mathrm{p}}{ }^{\prime \prime}\right)$ were used to determine the concentration of LYS.

\section{Results and discussion}

\subsection{Second order derivative linear sweep voltammogram}

Second order derivative linear sweep voltammetry, which is got by second order derivative of normal

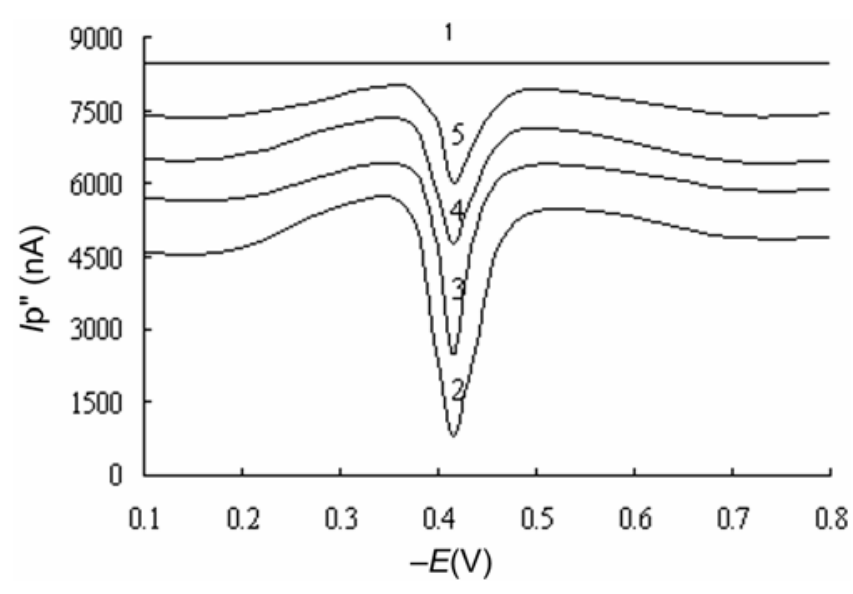

Figure 1. Second order derivative linear sweep voltammograms of ARS-LYS interaction system. 1. $\mathrm{pH} 4.8$ B-R buffer; 2 . $1+5.0 \times 10^{-5} \mathrm{~mol} / \mathrm{L} \mathrm{ARS} ; 3-5.2+10 \cdot 0$, $25 \cdot 0,30 \cdot 0 \mathrm{mg} / \mathrm{L} \mathrm{LYS}$. 
linear sweep voltammetric curve, was used throughout with the JP 303 polargraphic analyzer in all the experiments. Compared with the traditional linear sweep voltammetry, it has a well-defined peak shape with higher sensitivity and selectivity. Figure 1 showed the typical linear sweep voltammograms of ARS-LYS interaction solution. Curve 1 was the voltammogram of B-R buffer solution without any electrochemical responses, which indicated that no electroactive substances existed in the solution. Curve 2 was that of ARS in $\mathrm{pH} 4.8 \mathrm{~B}-\mathrm{R}$ buffer, a well-defined voltammetric peak appeared at $-0.42 \mathrm{~V}$ (vs SCE), which was due to the electrode reduction of the quinone group in the ARS molecular structure. Curve $3 \sim 5$ were that of ARS with the addition of different amounts of LYS. Due to the addition of LYS in the solution, a decrease of the reductive peak current appeared without the movement of the reductive peak potential. The more the LYS added, the greater the peak current decreased. As for the reason about the decrease of the peak current, there maybe due to the competitive adsorption or the interaction of ARS with LYS. Li et al had investigated the interaction of some electroactive dyes such as 9,10anthraquinone, tetraphenylporphyrin tetrasulfonate (TPPS) with proteins such as haemoglobin, albumin and antibody. ${ }^{24-26}$ The results indicated the at lower protein concentration and shorter mercury dropping standing period, the coverage of the electrode surface by adsorption only accounted for about $10 \%$ or less of the total electrode area. So the competitive adsorption between small molecules and protein could hardly exist and the decrease of the electro-

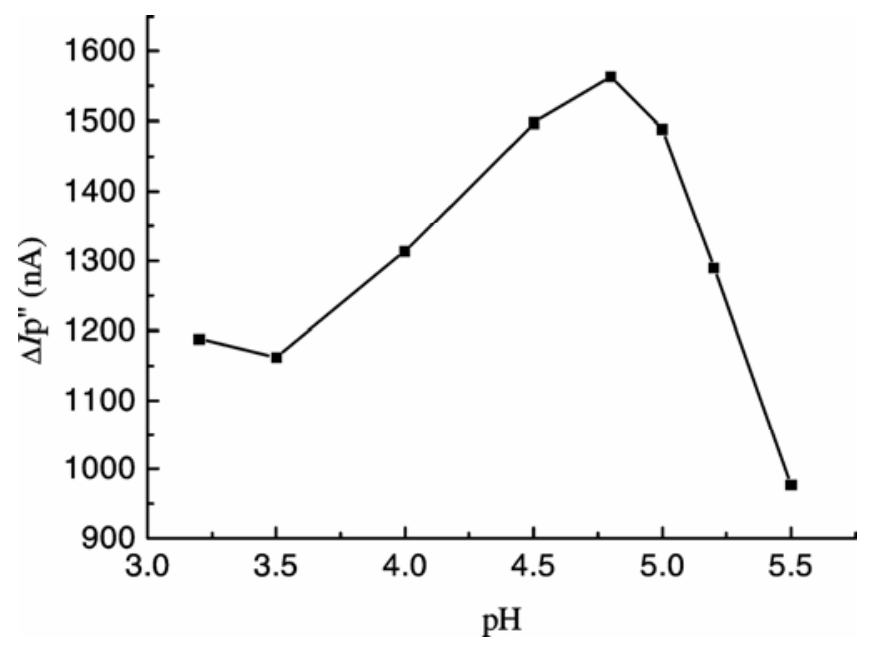

Figure 2. The influences of $\mathrm{pH}$ on the difference of peak current. $8.0 \times 10^{-5} \mathrm{~mol} / \mathrm{L}$ ARS $+50.0 \mathrm{mg} / \mathrm{L}$ LYS in different $\mathrm{pH}$ B-R buffer solution. chemical response was mainly attributed to the interaction of ARS and LYS in the solution. Based on the decrease of peak current, a new electroanalytical method could be further established for LYS determination.

\subsection{Optimization of the reaction conditions}

The $\mathrm{pH}$ of buffer solution greatly influenced the formation of ARS-LYS complex, so the influence of $\mathrm{pH}$ on the reaction was investigated. Figure 2 showed the relationship of $\mathrm{pH}$ with the changes of peak current. It could be seen that the value of $\Delta I p^{\prime \prime}$ increased at first and reached its maximum at $\mathrm{pH} 4.8$ and then decreased greatly, so $\mathrm{pH} 4.8 \mathrm{~B}-\mathrm{R}$ buffer solution was chosen as the optimal $\mathrm{pH}$. According to the reference, ${ }^{27}$ the $\mathrm{p} I$ of LYS was at $10 \cdot 7-11 \cdot 0$. When the $\mathrm{pH}$ was at 5.0 the conformational structure of LYS was consisted of the $\alpha$-helix and random coil, and the tyrosine residues were exposed. So at the selected $\mathrm{pH}$ value the LYS molecules were positively charged and the ARS molecules were negatively charged, it was possible for them to interact with each other by the electrostatic force. The amounts of buffer solution also affected the interaction and at the volume of B-R buffer ranged from 1.0 to $5.0 \mathrm{~mL}$, a maximum value of $\Delta l p^{\prime \prime}$ was got at $3.0 \mathrm{~mL}$ of $\mathrm{B}-\mathrm{R}$ buffer. Therefore $3.0 \mathrm{~mL}$ of B-R buffer solution was used in the subsequent investigation.

The effect of ARS concentration on the change of the peak current was studied by fixing the LYS concentration at $50.0 \mathrm{mg} / \mathrm{L}$. In the ARS concentration from $5.0 \times 10^{-6}$ to $2 \cdot 0 \times 10^{-4} \mathrm{~mol} / \mathrm{L}$, the value of $\Delta I \mathrm{p}^{\prime \prime}$ increased first and further decreased with the in-

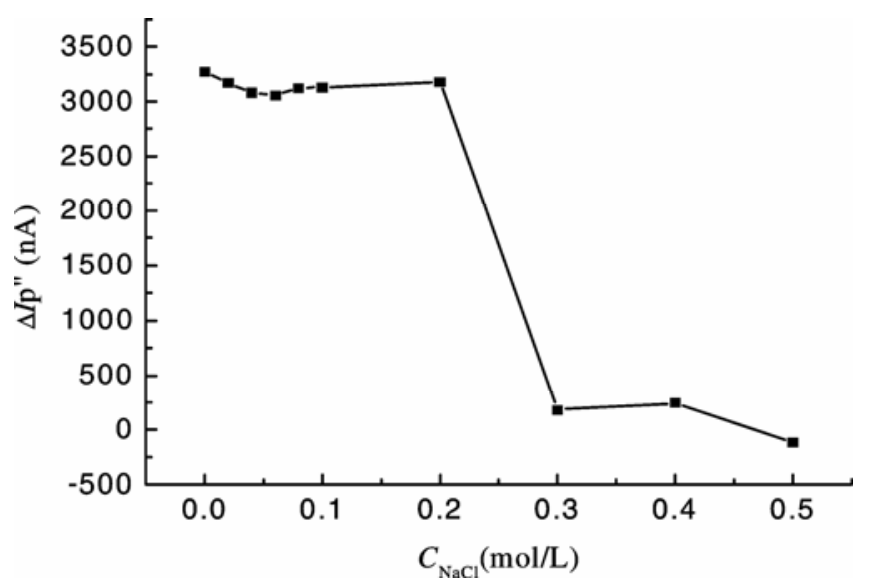

Figure 3. Effect of $\mathrm{NaCl}$ concentration on the differences of peak current. $\mathrm{pH} 4.8 \mathrm{~B}-\mathrm{R}+5.0 \times 10^{-5} \mathrm{~mol} / \mathrm{L}$ $\mathrm{ARS}+25.0 \mathrm{mg} / \mathrm{L} \mathrm{LYS}+$ different concentrations of $\mathrm{NaCl}$. 
crease of ARS concentration. The maximum value was got at the ARS concentration of $5.0 \times 10^{-5} \mathrm{~mol} / \mathrm{L}$, so this value was employed in the assay.

The reaction between ARS and LYS occurred rapidly at room temperature. Experimental results indicated that the reaction could reach its equilibrium within $20 \mathrm{~min}$ and the electrochemical response remained stable for about $2 \mathrm{~h}$. Therefore, the reaction system can be used for routine applications with ample time.

Different adding orders of ARS, LYS and B-R buffer were tested and the results showed that the best addition sequences were ARS, B-R buffer and LYS. The result indicated that the electronic coupling made ARS bind to LYS.

The instrumental conditions such as the scan rate and the dropping mercury static period for the assay were also studied. The reductive peak current increased gradually with the increase of the scan rate in the range from 300 to $1000 \mathrm{mV} / \mathrm{s}$. The peak current also increased with the increase of the dropping mercury static period in the range from 4 to $21 \mathrm{~s}$. So the scan rate and the dropping mercury static period were selected as $1000 \mathrm{mV} / \mathrm{s}$ and $21 \mathrm{~s}$, respectively.

\subsection{Effect of ionic strength and alcohol}

The effect of ionic strength on the formation of the biocomplex of LYS with ARS was studied by the addition of different amounts of $1.0 \mathrm{~mol} / \mathrm{L} \mathrm{NaCl}$ in the mixed solution and the results were shown in figure 3. The differences of peak current firstly

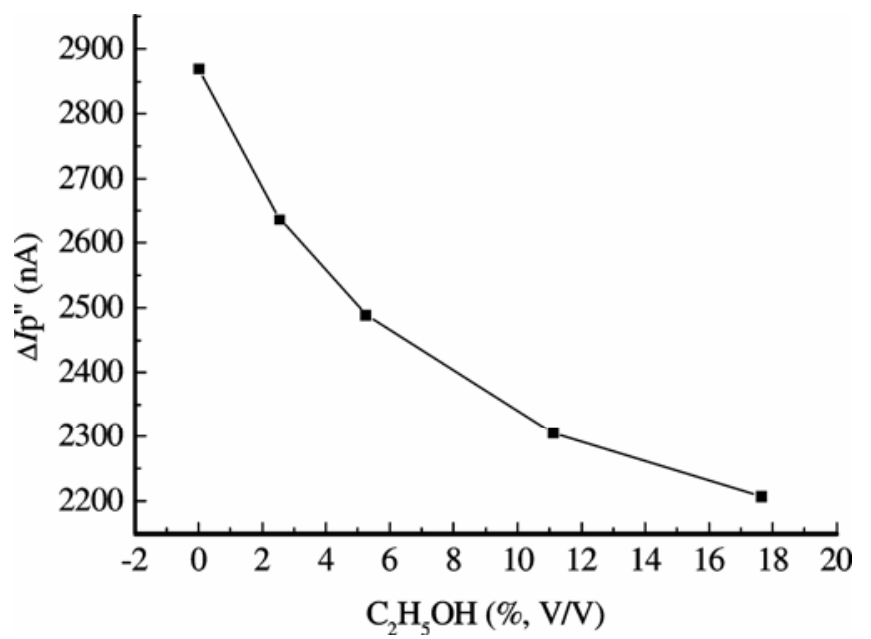

Figure 4. Effect of alcohol on the difference of peak current. pH $4.8 \mathrm{~B}-\mathrm{R}+5 \cdot 0 \times 10^{-5} \mathrm{~mol} / \mathrm{L} \mathrm{ARS}+25 \cdot 0 \mathrm{mg} / \mathrm{L}$ LYS + different amounts of alcohol. remained constant in the range from 0 to $0 \cdot 2 \mathrm{~mol} / \mathrm{L}$. When the concentration of $\mathrm{NaCl}$ was more than $0.2 \mathrm{~mol} / \mathrm{L}$ the response slowly decreased. It was obvious that the ionic strength had great effect on the binding reaction and the electrostatic forces were strong between ARS and LYS, which could be greatly influenced by the increase of the ionic strength. The more the $\mathrm{NaCl}$ added, the higher the ionic strength in the solution, the less the interaction of ARS and LYS, furthermore, the smaller the differences of peak current.

The effect of alcohol was further investigated and the result showed that alcohol also had great effect on the interaction. With the addition of alcohol, the value of $\Delta I \mathrm{p}^{\prime \prime}$ decreased greatly and the results were shown in figure 4 . This may be due to the differences in the dielectric constant of alcohol and water. The dielectric constant of alcohol was less than that of water. ${ }^{28}$ The solvent polarity of the system obviously decreased with the increase of the volume of alcohol. As a result, the polypeptide chains became more extended and the electrostatic force between LYS and ARS decreased, so the value of $\Delta I p^{\prime \prime}$ decreased.

\subsection{Determination of the binding constant and the binding ratio}

The stoichiometry of the ARS-LYS complex was further calculated from the voltammetric data. According to the reference, ${ }^{29}$ it was assumed that ARS and LYS could form a single complex of LYS$m$ ARS, where $m$ is the binding ratio. The following equations could be induced.

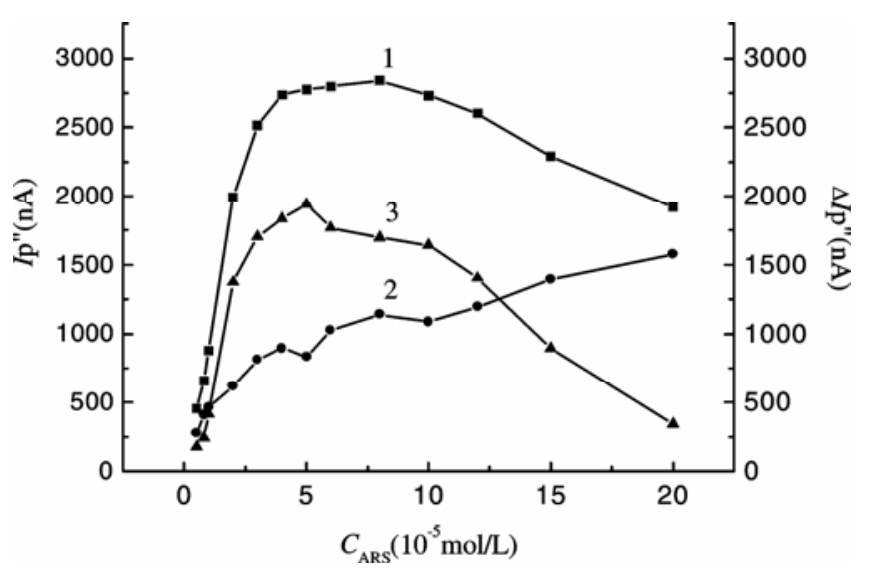

Figure 5. Relationship between $I \mathrm{p}^{\prime \prime}$ and $C_{\mathrm{ARS}}(1,2)$, $\Delta I \mathrm{p}^{\prime \prime}$ and $C_{\mathrm{ARS}}(3)$ in $\mathrm{pH} 4.8 \mathrm{~B}-\mathrm{R}$ buffer. 1. $C_{\mathrm{LYS}}=0 ; 2$. $C_{\mathrm{LYS}}=50 \cdot 0 \mathrm{mg} / \mathrm{L} ; 3 . \Delta I \mathrm{p}^{\prime \prime}=I \mathrm{p}_{1}{ }^{\prime \prime}-I \mathrm{p}_{2}{ }^{\prime \prime}$. 
Table 1. Tolerance of coexisting substances on the determination of $25.0 \mathrm{mg} / \mathrm{L} \mathrm{LYS}$.

\begin{tabular}{lccccc}
\hline $\begin{array}{l}\text { Coexisting } \\
\text { Substances }\end{array}$ & $\begin{array}{c}\text { Concentration } \\
(\mathrm{mg} / \mathrm{L})\end{array}$ & $\begin{array}{c}\text { Relative } \\
\text { error }(\%)\end{array}$ & $\begin{array}{c}\text { Coexisting } \\
\text { substances }\end{array}$ & $\begin{array}{c}\text { Concentration } \\
(\mu \mathrm{mol} / \mathrm{L})\end{array}$ & $\begin{array}{c}\text { Relative } \\
\text { error }(\%)\end{array}$ \\
\hline L-Glutamine & $2 \cdot 0$ & $2 \cdot 11$ & $\mathrm{Cu}^{2+}$ & $5 \cdot 0$ & $-2 \cdot 32$ \\
L-Tyrosine & $2 \cdot 0$ & $-2 \cdot 44$ & $\mathrm{Mn}^{2+}$ & $5 \cdot 0$ & $3 \cdot 71$ \\
L-Arginine & $2 \cdot 0$ & $3 \cdot 42$ & $\mathrm{Ca}^{2+}$ & $5 \cdot 0$ & $-1 \cdot 14$ \\
L-Leucine & $2 \cdot 0$ & $-0 \cdot 75$ & $\mathrm{Mg}^{2+}$ & $5 \cdot 0$ & $2 \cdot 93$ \\
L-Glutamic acid & $2 \cdot 0$ & $2 \cdot 14$ & $\beta-\mathrm{CD}$ & $5 \cdot 0$ & $0 \cdot 12$ \\
Glycine & $2 \cdot 0$ & $-1 \cdot 18$ & $\mathrm{SDS}$ & $5 \cdot 0$ & 3.99 \\
Glucose & $2 \cdot 0$ & $-2 \cdot 08$ & RNA & $2 \cdot 0(\mathrm{mg} / \mathrm{L})$ & 16.49 \\
BSA & $2 \cdot 0$ & -0.81 & DNA & $2 \cdot 0(\mathrm{mg} / \mathrm{L})$ & $15 \cdot 11$ \\
\hline
\end{tabular}

*BSA (bovine serum albumin), $\beta$-CD ( $\beta$-cyclodextrin), SDS (sodium dodecyl sulfate), RNA (ribonucleic acid), DNA (deoxyribonucleic acid)

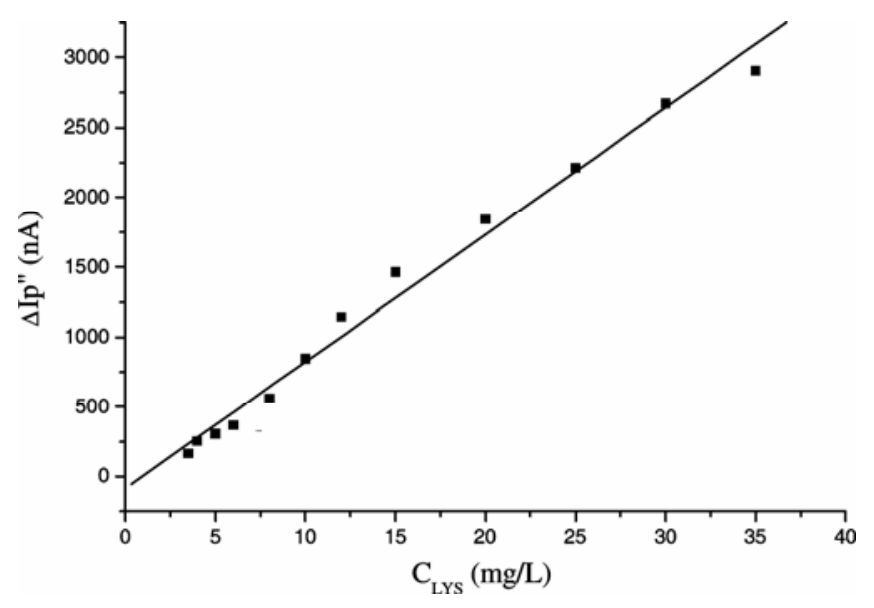

Figure 6. Relationship between peak current and the concentration of LYS with $5.0 \times 10^{-5} \mathrm{~mol} / \mathrm{L}$ ARS and $\mathrm{pH}$ $4 \cdot 8$ B-R buffer.

$$
\text { LYS }+m \text { ARS } \leftrightarrow \text { LYS- } m \text { ARS } .
$$

The binding constant $\left(\beta_{s}\right)$ could be obtained as follows:

$$
\beta_{\mathrm{s}}=\frac{[\mathrm{LYS}-m \mathrm{ARS}]}{[\mathrm{LYS}][\mathrm{ARS}]^{m}}
$$

Because of:

$$
\begin{aligned}
& \Delta I_{\max }=k C_{\mathrm{LYS}} \\
& \Delta I=k[\mathrm{LYS}-m \mathrm{ARS}] \\
& {[\mathrm{LYS}]+[\mathrm{LYS}-m \mathrm{ARS}]=C_{\mathrm{LYS}}}
\end{aligned}
$$

Therefore:

$$
\Delta I_{\max }-\Delta I=k\left(C_{\mathrm{LYS}}-[\mathrm{LYS}-m \mathrm{ARS}]\right)=k[\mathrm{LYS}] .
$$

Introducing (2), (4) and (6) gave:

$$
1 / \Delta I=1 / \Delta I_{\max }+\left(1 / \beta_{\mathrm{s}} \Delta I_{\max }\right)\left(1 /[\mathrm{ARS}]^{m}\right),
$$

or

$$
\log \left[\Delta I /\left(\Delta I_{\max }-\Delta I\right)\right]=\log \beta_{\mathrm{s}}+m \log [\text { ARS }] .
$$

where $\Delta I$ was the difference of peak current in the presence and absence of LYS, $\Delta I_{\max }$ corresponded to the obtained value when the concentration of ARS was extremely higher than that of LYS. $C_{\mathrm{LYS}}$, [LYS], [LYS - mARS] were corresponding to the total, free and bound concentration of LYS in the solution, respectively.

According to this method, the relationship of the peak current with the concentration of ARS was plotted and the results were shown in figure 5 , it could be seen that the reductive peak current increased with the increase of the ARS concentration (curve 1). By fixing the concentration of LYS at $50.0 \mathrm{mg} / \mathrm{L}$, the peak current of the reaction solution was also increased with the increase of ARS concentration (curve 2). But the difference of peak current $\left(\Delta I \mathrm{p}^{\prime \prime}\right)$ increased with the increase of LYS concentration firstly and reached the maximum value at the ARS concentration of $5.0 \times 10^{-5} \mathrm{~mol} / \mathrm{L}$ (curve 3). When the ARS concentration was more than $5.0 \times$ $10^{-5} \mathrm{~mol} / \mathrm{L}$, the value of $\Delta \mathrm{lp} \mathrm{p}^{\prime \prime}$ decreased, which indicated that the LYS molecule had been completely interacted with ARS.

By exploring the relation of $\log \left[\Delta I /\left(\Delta I_{\max }-\Delta I\right)\right]$ with the $\log [\mathrm{ARS}]$, a linear regression equation was got as $\log \left[\Delta I /\left(\Delta I_{\max }-\Delta l\right)\right]=3 \cdot 0 \log [\mathrm{ARS}]+14 \cdot 5(n=5$, $\gamma=0.9997)$. From the intercept and the slope the value of $m$ and $\beta_{\mathrm{s}}$ were got as 3.0 and $3.16 \times 10^{14}$, respectively, which indicated a stable LYS-3ARS complex was formed in the selected conditions.

\subsection{Analytical application}

Based on the decrease of peak current with the concentration of LYS, a sensitive linear sweep voltam- 
Table 2. Determination results of LYS in artificial samples $(n=3)$.

\begin{tabular}{lccccc}
\hline Sample & Coexisting substances & $\begin{array}{c}\text { Added } \\
(\mathrm{mg} / \mathrm{L})\end{array}$ & $\begin{array}{c}\text { Found } \\
(\mathrm{mg} / \mathrm{L})\end{array}$ & $\begin{array}{c}\text { Recovery } \\
(\%)\end{array}$ & RSD (\%) \\
\hline 1 & $\mathrm{Ca}^{2+}, \mathrm{Cu}^{2+}, \mathrm{L}$-Leucine, L-Glutamic acid & $25 \cdot 0$ & $25 \cdot 81$ & $103 \cdot 22$ & $2 \cdot 96$ \\
2 & $\mathrm{Cu}^{2+}, \mathrm{Mg}^{2+}, \mathrm{L}-\mathrm{L}$ (\%cine, L-Glutamine, Glucose & $25 \cdot 0$ & $26 \cdot 51$ & $106 \cdot 04$ & $2 \cdot 13$ \\
\hline
\end{tabular}

metric method for LYS determination were established in the concentration range from 0.8 to $35.0 \mathrm{mg} / \mathrm{L}$ with the results shown in figure 6 . The linear regression equation was got as $\Delta I \mathrm{p}^{\prime \prime}(n A)=$ $92.50 C(\mathrm{mg} / \mathrm{L})-107.82(n=12, \gamma=0.9954)$ and the detection limit was calculated as $0.52 \mathrm{mg} / \mathrm{L}(3 \sigma)$. The relative standard deviation (RSD) for 10 parallel determinations of $25.0 \mathrm{mg} / \mathrm{L}$ LYS was got as $0.50 \%$.

The influences of various potential coexisting substances, such as amino acids and metal ions which may exist in the biosamples, on the determination of $25.0 \mathrm{mg} / \mathrm{L}$ LYS were investigated. The results were shown in table 1 and few of them had effect on the determination. But the presence of biomolecules such as RNA and DNA greatly influenced the detection, which may be due to the interaction of them with ARS.

The proposed method was further applied to the sample determination. Two artificial samples were determined according to the general procedure and the results were listed in table 2. It could be seen that LYS in synthetic samples could be determined with satisfactory results and the recovery was in the range of 103.22 to $106.04 \%$.

The lysozyme buccal tablets sample (H33021361, 12500 U/per tablet, Guoguang Pharmaceutical Company of China) was also detected by this method. The tablet was carefully dissolved, diluted and applied in the general procedure. The results of determination was in accordance with the specified amount with the RSD as $2.35 \%$ and the recovery as $95.80 \%$, so this new method was practical and reliable.

\section{Conclusion}

In this paper the interaction of ARS and LYS was studied by linear sweep voltammetry and further used for LYS detection. The proposed electroanalytical method was simple, rapid and reliable. The stoichiometry of the ARS-LYS complex was calculated by the voltammetric data. This new method was suc- cessfully applied to the determination of the synthetic and real tablet samples.

\section{Acknowledgement}

This work has received support from the National Natural Science Foundation of China (20405008).

\section{References}

1. Bradford M M 1976 Anal. Biochem. 72248

2. Wei Y J, Li K A and Tong D Y 1996 Talanta 431

3. Gao H W and Zhao J F 2003 J. Chin. Chem. Soc. 50 329

4. You W W, Hanglang R P, Ryan D K and Haugland R P 1997 Anal. Biochem. 244277

5. Ma C Q, Li K A and Tong S Y 1996 Anal. Chim. Acta $\mathbf{3 3 3} 83$

6. Cao Q E, Ding Z T, Fang R B and Zhao X 2001 Analyst 1261444

7. Yao G, Li K A and Tong S Y 1999 Talanta 50 585

8. Sun W, Jiao K, Wang X L and Lu L D 2005 J. Electroanal. Chem. $\mathbf{5 7 8} 37$

9. Sun W, Jiao K, Han J Y and Xu G Y 2006 J. Chin. Chem. Soc. 531141

10. Wang J 2000 Analytical electrochemistry, Second Edition (New York: Wiley-VCH) p. 1

11. Kobayashi M, Kusakawa T, Saito M, Kaji S, Oomura M, Iwabuchi S, Morita Y, Hasan Q and Tamiya E 2004 Electrochem. Commun. 6337

12. Li Y J, Guo Y J, Li X F and Pan J H 2007 Talanta 71 123

13. Jiao K, Wang Q X, Sun W and Jian F F $2005 J$. Inorg. Biochem. 21145

14. Sun W, Han J Y, Ren Y and Jiao K 2006 J. Braz. Chem. Soc. 17510

15. Sun W, Jiao K, Han J Y and Lu L D 2006 Bioelectrochemistry 6860

16. Sun W, Ding Y Q and Jiao K 2006 J. Anal. Chem. 61 359

17. Sun W, Ding Y Q and Jiao K 2006 Electroanalysis 181114

18. Lu F, Pan J H, Liu Y, Zhang H F, Guo Y J and Wang Y T 2006 Biochem. Cell Biol. 841

19. Warren J S, Rinehart J J, Zwilling B S and Neidhart J A 1981 Cancer Res. 411642 
20. Wang D L 2003 Chin. Biotechnol. 2359

21. Chen X L, Yu F, Qu L B and Zhao Y F 2004 Acta Chim. Sinica 62188

22. Yang R, Qu L B, Chen X L, Li J J and Li P 2006 Acta Chim. Sinica 641349

23. Wang X M 2005 Chin. J. Inorg. Chem. 21315

24. Zhang H M, Zhu Z W and Li N Q 1999 Fresenius's J. Anal. Chem. 363408
25. Zeng Y N, Liu J Y and Li Y Z 2002 Electrochem. Commun. 4679

26. Zhu Z W and Li N Q 1999 Microchim. Acta 130301

27. Heng H, Ke W Z and Ji K 2006 J. Nanjing Normal Univ. 2948

28. Hu Q L, Zhao F L and Li K A 1999 Acta Scientiarum Naturlium Universitatis Pekinensis 359

29. Li N Q and Min J 1989 Chin. J. Anal. Chem. 17346 